Trauma Surgery $\&$ Acute Care Open

\title{
Beware the circular saw
}

\author{
David J Skarupa, ${ }^{1}$ David V Feliciano ${ }^{2}$
}

'Department of Surgery, University of Florida College of Medicine, Jacksonville, Florida, USA

${ }^{2}$ University of Maryland School of Medicine, Baltimore, Maryland, USA

Correspondence to Dr David J Skarupa; david. skarupa@jax.ufl.edu (c) Author(s) (or their employer(s)) 2021. Re-use permitted under CC BY-NC. No commercial re-use. See rights and permissions. Published by BMJ.

\section{To cite:}

Skarupa DJ, Feliciano DV.

Trauma Surg Acute Care Open 2021;6:e000704.

\section{HISTORY}

While a young right-hand dominant man was working on a job site with power tools, a circular saw cut his left distal volar forearm. A pressure dressing was applied, and he was transported to the trauma center. The patient reported a significant amount of blood loss at the scene.

\section{EXAMINATION}

The patient was awake and alert, and his primary survey was intact. On exposure, he had a transverse laceration to his distal left volar forearm that extended from the radial to ulnar side (figure 1). No bleeding was seen at the site of injury, but pulses were absent. Pulse oximetry of the fingers was decreased on the left (92\%), as compared with the right hand (100\%).

\section{QUESTION}

What would be your next step in management?

1. Explore wound at bedside.

2. Close skin and follow-up as outpatient.

3. CT arteriogram left upper extremity.

4. Explore wound in the operating room.

\section{MANAGEMENT}

The patient was taken to the operating room without further diagnostic imaging. Based on the extent and location of the injury, as well as the findings on physical examination, the patient was presumed to have at least one, and, possibly, two arterial injuries at the wrist (radial and ulnar arteries).

The entire left upper extremity and both lower extremities were prepared and draped in a sterile fashion. The incision was extended proximally and distally, along a standard volar forearm ' $\mathrm{S}$ ' incision for full exploration. The radial artery was identified and found to be transected, while the ulnar artery was found to be nearly transected. Proximal and distal arterial control was obtained with bulldog clamps.

\section{QUESTION}

What would be your next step in management?

1. Ligate and tag vessels for later vascular reconstruction.

2. Place shunt in each artery.

3. Repair one artery and ligate the other.

4. Repair both arteries and systemically heparinize.

\section{MANAGEMENT}

After systemic heparin was administered intravenously (7000 units, approximately $100 \mathrm{U} / \mathrm{kg}$ ), the radial and ulnar arteries were mobilized proximally and distally. A 2 Fr Fogarty balloon catheter was passed proximally and distally into both arteries, some thrombus was removed, and inflow from both vessels was brisk. The ulnar artery was debrided, and a spatulated end-to-end anastomosis was performed with 6-0 Prolene sutures and a total of 4 knots located at $90^{\circ}$ apart on the anastomosis. After reconstruction of the ulnar artery, retrograde flow was present through the distal radial artery. A 2 Fr Fogarty balloon catheter was passed once again through the proximal radial artery. The radial artery was then debrided, and a spatulated end-to-end anastomosis was performed with 7-0 Prolene in the same fashion as described for the ulnar artery (figure 2). Papaverine solution $(60 \mathrm{mg}$ in $250 \mathrm{~mL}$ of normal saline) was applied externally to both anastomoses. Once the anastomoses were completed the palmar arch was evaluated. With occlusion of the ulnar artery there was a strong signal distal to the anastomosis of the radial artery and, with occlusion of the radial artery, there was a good signal distal to the anastomosis of the ulnar artery.

Additional injuries included the following: median nerve, flexor pollicis longus, flexor digitorum superficialis, flexor carpi radialis and palmaris longus. These injuries were all repaired by orthopedic hand surgery the following day.

The patient received systemic anticoagulation (heparin) and aspirin $81 \mathrm{mg}$ orally daily postoperatively. He was transitioned to apixaban (Eliquis) and aspirin $81 \mathrm{mg}$ orally daily at discharge.

At a clinic visit 6 weeks after discharge, his left hand had some muscle atrophy, but appeared well perfused. He had equal pulse oximetry readings on bilateral thumbs and long fingers, as well as symmetric brisk capillary refill. The left radial pulse was palpable despite pitting edema at the wrist. An Allen's test ${ }^{1}$ was performed on the injured hand, and it demonstrated an intact arterial tree with pallor quickly replaced by rubor, and then rubor fading to normal color (figure 3). This was symmetric when compared with the results of the Allen's test on the uninjured hand. Using a Doppler device in the office, radial and ulnar artery signals were the same on the left wrist as compared with the right. Surveillance arterial duplex of the arterial reconstruction showed the normal triphasic wave forms with no elevated velocities, suggesting no stenosis in the reconstruction (figure 4).

\section{DISCUSSION}

An injury to the radial or ulnar artery is usually not a threat to the hand. This is obviously due to the dual blood flow to the hand, as well as the interosseous arteries (anterior and posterior branches). Management of injuries to the named arteries of the forearm varies from reconstruction to ligation. Ligation of one of the arteries is an acceptable option as 


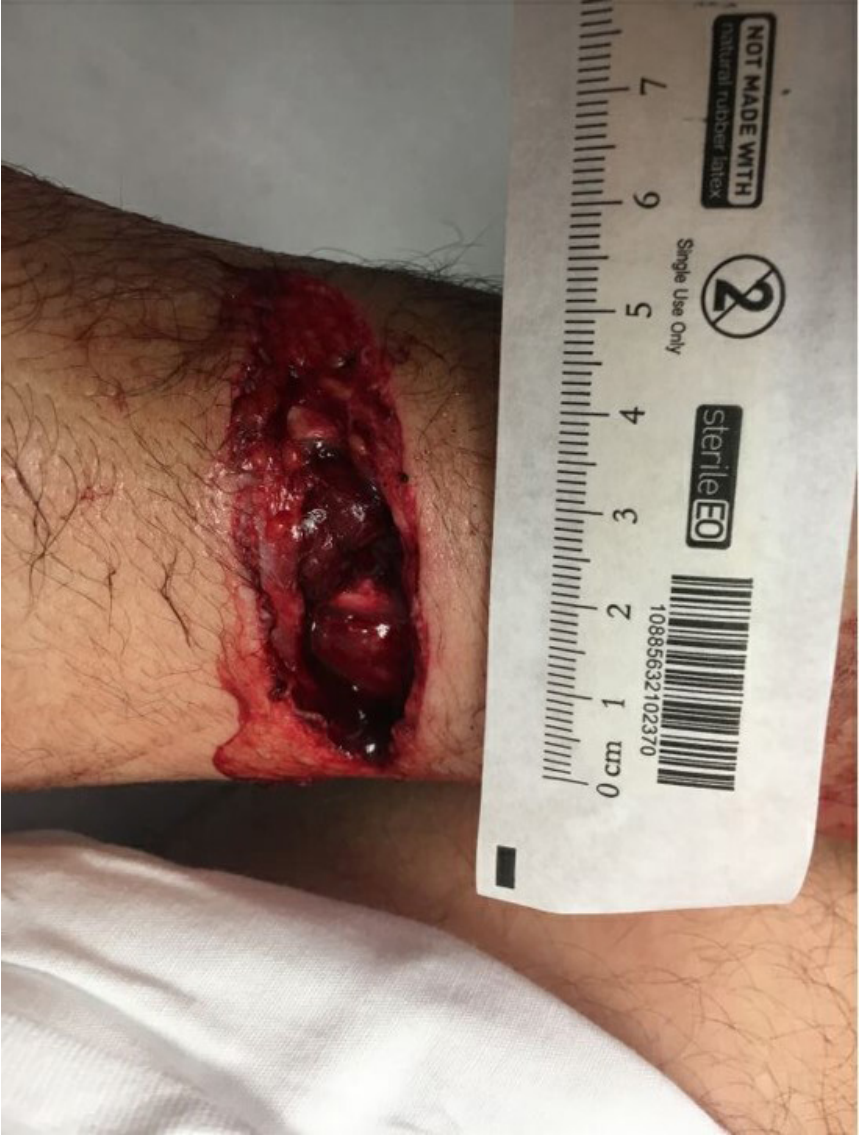

Figure 1 Appearance of injury to the volar left forearm.

it is simple and safe if the palmar arch is intact. ${ }^{2-4}$ Reconstruction of forearm vessels, however, can be challenging due to the small caliber of the vessels and potential for vasospasm. In the patient described, ligation was not an option as both arteries were severely injured in the distal forearm.

Mobilization of both injured arteries allowed for spatulated end-to-end anastomoses. The authors acknowledge that continuous suture lines in circular structures can cause a 'pursestring effect' and narrow the lumen and that anastomoses in microsurgery, surgery on small vessels, and vascular repairs in children

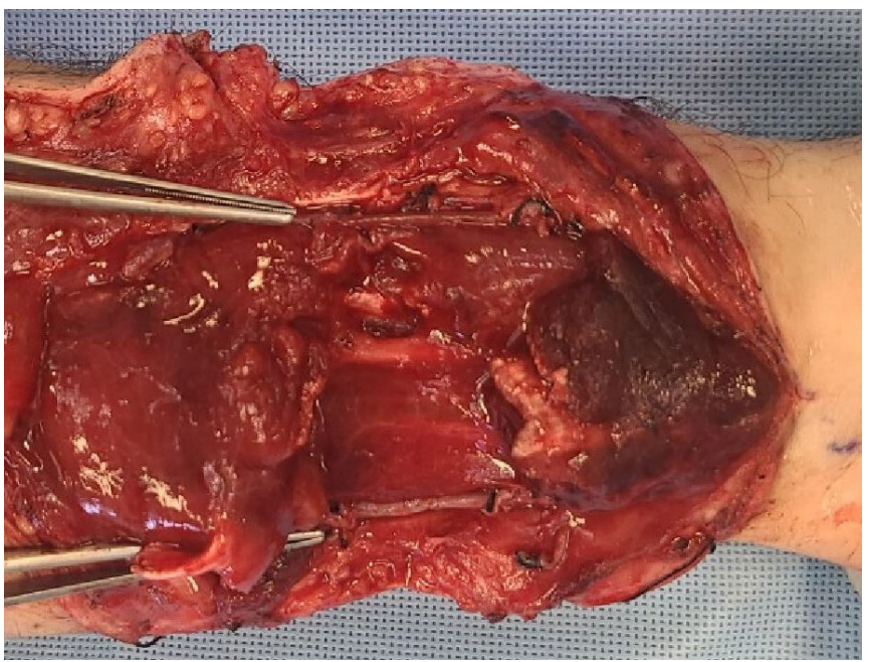

Figure 2 Intraoperative photo after radial and ulnar artery reconstruction.

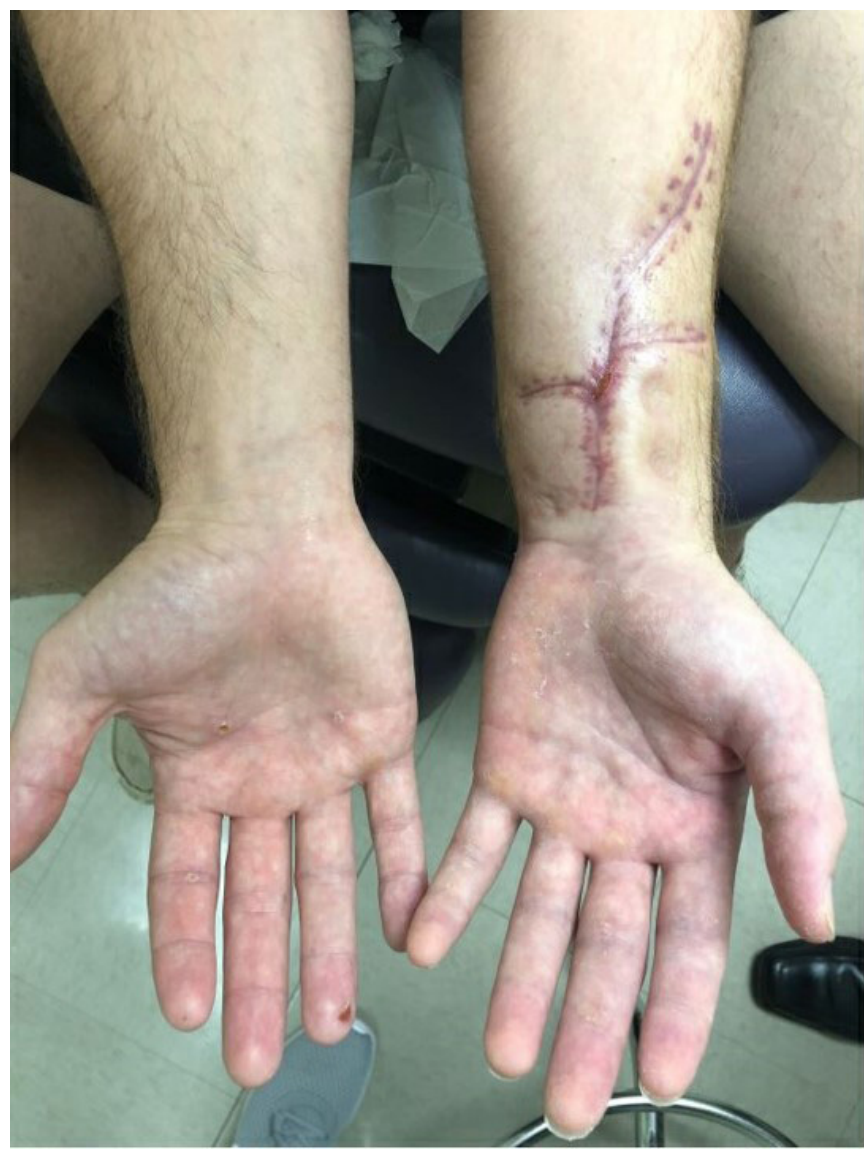

Figure 3 Postoperative visit 6 weeks from reconstruction showing both hands after Allen's test.

are often performed with interrupted sutures with beveled anastomoses. The anastomoses described were extremely spatulated and completed with meticulous suture and knot placement to avoid 'pursestringing' the anastomosis.

Other options for arterial reconstructions are arterial interposition grafts. Arterial grafts seem to have a higher patency rate compared with vein grafts in upper extremity vascular surgery. ${ }^{56}$ Most of the data are in age-related or autoimmune conditions, though, and not applicable to reconstruction of the ulnar and radial arteries at the wrist after trauma. Applying principles of vascular surgery, arterial patency is greatest for primary repair or artery-to-artery reconstructions.

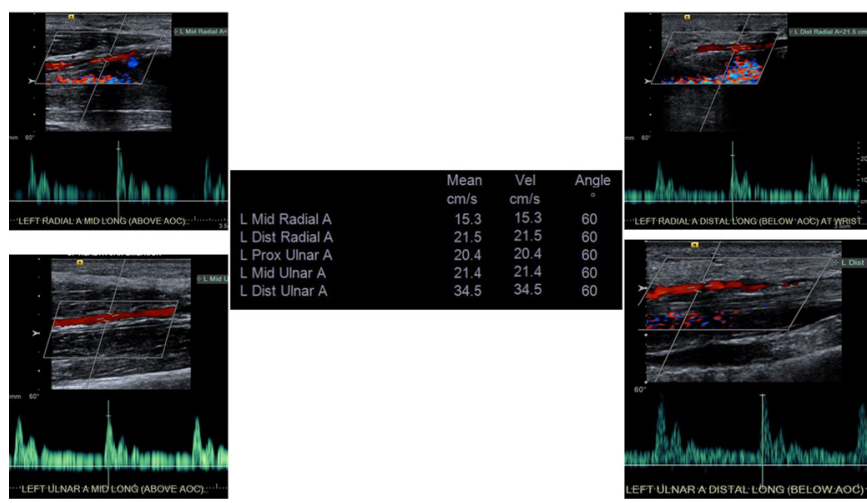

Figure 4 Doppler ultrasound data 6 weeks after surgery showing no clinically significant elevated arterial velocities distal to the anastomoses. 


\section{CONCLUSION}

Viability of the hand is severely compromised with ligation of both injured ulnar and radial arteries. Repair of the ulnar artery, the main flow into the palmar arch, should be performed with standard vascular techniques in such patients. Repair of an associated injury to the ipsilateral radial artery will depend on the size and condition of the vessel, the hemodynamic status of the patient, and the surgeon's expertise with and enthusiasm for small vessel repair. Meticulous attention to techniques of arterial reconstruction is imperative for a successful outcome.

Funding The authors have not declared a specific grant for this research from any funding agency in the public, commercial or not-for-profit sectors.

Competing interests None declared.

Patient consent for publication Not required.

Provenance and peer review Commissioned; internally peer reviewed.
Open access This is an open access article distributed in accordance with the Creative Commons Attribution Non Commercial (CC BY-NC 4.0) license, which permits others to distribute, remix, adapt, build upon this work non-commercially, and license their derivative works on different terms, provided the original work is properly cited, appropriate credit is given, any changes made indicated, and the use is non-commercial. See: http://creativecommons.org/licenses/by-nc/4.0/.

\section{REFERENCES}

1 Allen EV. Thromboangitis obliterans: methods of diagnosis of chronic occlusive arterial lesions distal to the wrist with illustrative cases. Am J Med Sci 1929:237-44.

2 Johnson M, Ford M, Johansen K. Radial or ulnar artery laceration. Arch Surg 1993;128:971-4.

3 Ballard JL, Bunt TJ, Malone JM. Management of small artery vascular trauma. Am J Surg 1992;164:316-9.

4 Aftabuddin M, Islam N, Jafar MA, Haque E, Alimuzzaman M. Management of isolated radial or ulnar arteries at the forearm. J Trauma 1995;38:149-51.

5 Shuck J, Masden DL. Options for revascularization: artery versus vein: technical considerations. Hand Clin 2015;31:85-92.

6 Masden DL, Seruya M, Higgins JP. A systematic review of the outcomes of distal upper extremity bypass surgery with arterial and venous conduits. J Hand Surg Am 2012:37:2362-7. 